those previously discussed. One such system, wrist rotation, is arrived at in the final section on the hand, where the error signal is generated as the visual separation between controlled and target pointers. The dynamics of muscular control are seen by the author to arise from the basic interaction of the proprioceptively closed postural control loop and the proprioceptively open voluntary control loop. After a discussion of the system elements involved, the frequency and phase responses of the overall system are obtained and compared with particular cases of clinical interest where Parkinson's syndrome is present. Further interesting experiments, which demonstrate the relatively minor part played by eye positioning in coordinated control, are reported and lead to a proposed model for the wrist-rotation system.

This book is a welcome amalgamation of the cybernetic studies in which Stark has been involved over a period of many years. His work, as judged by those interested in the future of eyberneties, can bo regarded as no less than exemplary in confronting the physiologist with tangible and relevant examples which embrace the challenging ideas of cybernetics. As with any interdisciplinary subject, particular care is needed in addressing readers of different disciplines and his book would perhaps be appreciated by a wider section of life scientists if a more gentle introduction to the necessary mathematics had been included. Nevertheless, the book amply illustrates the enhancement of quantitative neurophysiological studies that results from the use of control theory, information theory, mathematical models and the computer used in various roles. Perhaps the point of greatest single portent is, however, to illustrate that the application of engineering science may extend the bounds of conventional neurophysiology towards functional studies of the animal and human brain that involve neither surgical nor pharmacological artefact.

W. J. Perkins

B. J. HAMMOND

\section{BARTRAM'S DRAWINGS}

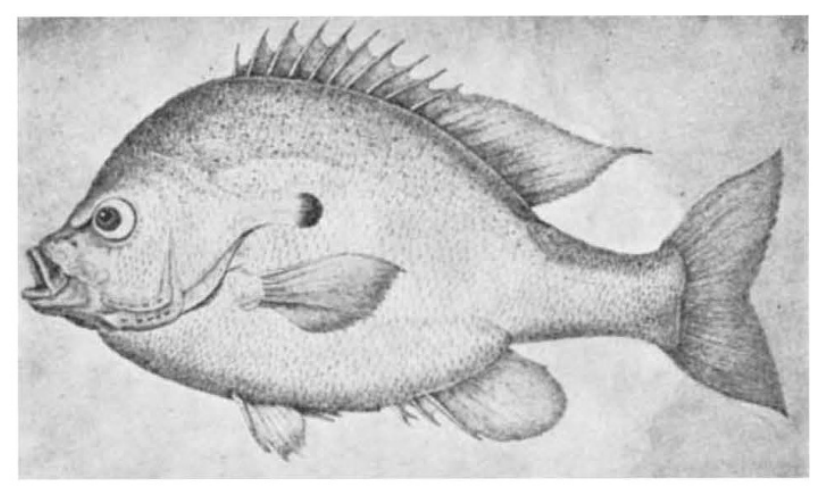

William Bartram of Philadelphia (1739-1823) was the first native-born American artist-naturalist. From 1766 to 1779 , he was engaged by Dr John Fothergill of London, a Quaker physician very interested in American natural history, to collect plants and seeds for Fothergill's botanical garden in Surrey. On three journeys through Florida, Georgia, Alabama, South Carolina and North Carolina, Bartram not only collected specimens but also made numerous illustrations of plants and animals for Fothergill, the Duchess of Portland, and other English enthusiasts. Those made for Fothergill, bound together in an album, finally came into the keeping of the Botanical Library of the British Museum (Natural History). The American Philosophical Society, to which both Bartram and Fothergill belonged, has now published the drawings in their original size and colour with an introduction and commentary by Joseph Ewan (William Bartram: Botanical and Zoological Drawings, 1756-1788. American Philosophical Society: Philadelphia, 1968, \$35).

\section{MARINE STUDIES}

\section{Advances in Marine Biology}

Vol. 6. Edited by Sir Frederick S. Russell and Sir Maurice Yonge. (Academic Press: London and New York, December 1968.) 126s; $\$ 17.50$.

THe combination Russell and Yonge has been familiar to all marine biologists since the appearance of The Seras in 1928; to one who was privileged to be a junior bottlewasher to both of them, it is good to see Sir Frederick and Sir Maurice collaborating, forty years later, as editors of this admirable series of Advances in Marine Biology.

This, the sixth in the series, contains three large articles (one, on mangroves, being of book length). The first is a sombre, even depressing account of the need for "Management of Fishery Resources" by Gulland and Carroz of the FAO. Near the beginning is a world map showing twenty-seven fish stocks in the high seas which in 1949 were believed to be underfished; twelve of these (six in the North Atlantic alone) are now in danger of over-exploitation. The final sentence reads: "Without some fundamentally new approach it is doubtful if the fisheries of the world can maintain their recent record of increasing production faster than the increase in world population". In between, there are discussions on the need for management, on methods of regulation, on international law, and on problems and prospects for future progress. There is an informative comparison of the striking success of management of the Pacific fur seal, the partial success with the Pacific halibut, and the dismal failure in whaling. An appendix lists the international bodies concerned with fisheries management; these are now numerous, and seem to overlap a good deal. One can only hope that this important paper receives, and holds, the attention of fisheries administrators throughout the world.

The middle and longest section of the volume is an exhaustive account by $\mathrm{W}$. Macnae of the mangrove forests in the Indo-West-Pacific and their inhabitants--. fascinating reading to anyone who has been inside a mangrove swamp. These swamps comprise a unique environment, where several species of trees are invading the sea, many different crabs have more or less become land animals, marine gastropods climb trees, mud-skipping gobies spend much of their time out of the water, and mosquitoes not only breed in salt water but even suck the blood of the gobies. The author deals in great detail with the plants of the mangrove swamps and their zonation and successions, with the land and marine animals and their habits, and with the mutual ecological relationships of them all; attention is called, too, to point after point which needs further investigation. The final section is an interesting one on the products made by man from mangroves, which include ships' masts, chareoal, and even, in Queensland, honey. There is a huge bibliography of some 30 pages, from which there is one curious omission: the author refers, as such, to "the Island Reefs" of the Queensland coast, and includes several recent illust rations of Low Isles, but makes no mention of the classical description of these reefs by Spender in the Geographical Journal of 1930.

The final paper is by E. Ghirardelli on that still enigmatic little phylum, the chaetognaths or arrow worms. For once, members of this group are treated not as plankton or as "indicator" species, but as animals in their own right; classical zoology, in fact. There is a useful general introduction to their morphology, and this is followed by the main section, on reproduction-male and fomale genital apparatus, gametogenesis, firtilization (a fascinat ing section, this), egg-laying, and sexual cycles. It is good to learn that various scientists can now keep several planktonic species alive long enough to make critical observations in vivo. There is a learned discussion on affinities and systematic position, but even Ghirardolli is unable to link the chaetognaths to any other phylum. 